NOMENCLATURE

Edited by John McNeill, Anthony E. Orchard \& John C. David

\title{
Latin diagnoses: An unnecessary impediment - A response to Jørgensen
}

\author{
Estrela Figueiredo, ${ }^{1}$ Gerry Moore ${ }^{2}$ \& Gideon F. Smith ${ }^{3}$ \\ 1 H.G.W.J. Schweickerdt Herbarium, Department of Plant Science, University of Pretoria, Pretoria, 0002 South Africa \\ 2 Brooklyn Botanic Garden, 1000 Washington Avenue, Brooklyn, New York 11225 U.S.A. \\ 3 Office of the Chief Director: Biosystematics Research \& Biodiversity Collections, South African National Biodiversity Institute, \\ Private Bag X101, Pretoria, 0001 South Africa / Acocks Chair, H.G.W.J. Schweickerdt Herbarium, Department of Plant Science, \\ University of Pretoria, Pretoria, 0002 South Africa \\ Author for correspondence: Estrela Figueiredo, estrelafigueiredo@hotmail.com
}

\begin{abstract}
We conclude that the arguments put forward by Jørgensen in his response to our recent proposal to abandon botanical Latin as the mandatory language in which to provide a description or diagnosis when a new species is described, in fact serve to confirm that this requirement must now be removed from the International Code of Botanical Nomenclature.
\end{abstract}

Keywords Botanical Latin; botanical nomenclature

There is no doubt that the little note on botanical Latin that Jørgensen (2010) wrote will go down in nomenclatural history as the least satisfactory ever written on the subject. Hardly any new perspectives are offered and his suggestions are weak and unconvincing. He goes further by unambiguously including the statement "a necessary evil" in the title of his paper. An evil (the Latin diagnosis, that is) therefore that "has served us well", according to him. This surely must be one of the most glaring contradictions in terms ever to have appeared in the pages of Taxon. One must inevitably ask to what extent botanical Latin is currently serving us well?

We do not agree with the reasoning given by Jørgensen that we should keep botanical Latin so as to "keep us [presumably the global taxonomic community] in contact with the past where much of botanical terminology was established." Today comprehensive botanical glossaries are widely available in scores of languages. These most certainly provide sufficient links with the past, should anyone desire access to information on botanical terminology. What does the author mean by a "tradition which secures reliable nomenclature"? Botanical nomenclature is 'secured' by its Code, not by traditions. However, it is interesting that the author sees the Latin diagnosis as a mere tradition. Traditions are ever so often obsolete (and in many instances harmful) practices kept alive for sentimental reasons. For some traditions there is simply no place in science.

We were also struck by the phrase "Classical Latin is a dead language because nobody is using it!", a truism that will also probably go into Taxon's records as one of the most futile statements ever made in this learned journal in support of the retention of a derivative of that very same (dead) language. Do we really have to keep botanical Latin alive because classical Latin is dead? This surely must be a non-argument.
Maintaining obsolete practices will ultimately prove to be stifling to progress in botanical nomenclature. Of course taxonomists are bound by history and virtually every new species described, any name sunk, and every revision completed builds on a history (often, if not invariably) dating back to 1753 (and sometimes even earlier).

The author states that the Latin diagnosis "cannot be substituted by a description which entirely belongs in the sphere of taxonomy". It is regrettable that the author appears to ignore the fact that the diagnosis is in fact not mandatory in the present Code as it can indeed be replaced with a full Latin description. It is not the diagnosis that is mandatory, it is the Latin!

One of the keywords of Jørgensen's paper is "precision". This concept does not reappear in the three paragraphs that constitute his short note. On the contrary, it is deliberately proposed that "examples of diagnoses" should be posted on the web, which is one of the most outrageous ideas supporting imprecision we have ever come across. Should such a proposal be implemented it will come down to nothing less than legalizing the widespread copying of diagnoses for new taxa being described, which surely will happen. This practice may now be common out of pure necessity, but must be seriously discouraged, indeed severely reprimanded. The reality is that many editors and reviewers will probably not notice or realize that diagnoses are being copied, unless a google (or similar) worldwide-web search facility is used. At any rate, thousands of diagnoses are indeed already available on the web, for example through the admirable electronic dissemination of protologues. Precision as far as the construction of botanical Latin diagnoses is concerned is a distant memory, at best, and the link between these and reliable nomenclature has been tenuous for some time. Much rather, it is the Code itself that should be precise, and simple, for that matter. 
The only idea produced in this contradictory text is the suggestion of "establishing a multilingual, user-friendly guide to botanical Latin on the Internet with examples of diagnoses". Obviously, a multilingual guide to botanical terms would also serve the purpose of translating the diagnosis from any language into one's own. Why would it work only for botanical Latin? Furthermore, with such a tool there would be no danger of falling into the so-much feared 'Babylonian confusion' as any diagnosis could be easily and automatically translated into any other language. Again, a non-argument.

Following an invitation by a prominent botanical institution to approach them for assistance with writing diagnoses for novelties being described, a patently wrong diagnosis was recently received. Unsurprisingly, the inability to write coherent, informative diagnoses is even more widespread than is currently widely known. A further paper in which a new species was described was received back with the comment that "the botanical Latin diagnosis must be corrected". The diagnosis was written by one of the last Latin scholars in South Africa. Neither the editor, nor the referees, had any knowledge of Latin, yet we were told to "correct the Latin".

Two of us (GFS and EF) have a strong interest in the taxonomy and systematics of the subfamily Alooideae of the Asphodelaceae, a group with about 800 species which are largely restricted to southern Africa and other parts of the Old World. The subfamily has attracted considerable attention from succulent plant collectors and researchers across the globe and at least three journals (Haworthiad [United Kingdom], Alsterworthia International [United Kingdom], Haworthia Study [Japan]) that deal almost exclusively with aspects of the biology and taxonomy of the alooids have been established over the past 20-odd years. Several new entities have been described in the Japanese journal in especially the genus Haworthia Duv. Although these novelties are accompanied by botanical Latin diagnoses and brief English text, the full species discussions are almost invariably in Japanese, not a language that any of us are familiar with. Translation of the Latin diagnoses does nothing to clarify the circumscription of these new species and other taxa of lower rank, nor was it intended to. Translation of the descriptive Japanese texts is inevitable if future researchers are to make sense of the new names. It may be an imposition, but it is a reality. Deal with it. In fact, the diagnoses in Latin are little more than an irritation for the describing author and are mostly ignored by the readers.

We have no intention of here repeating the arguments we previously refuted for retaining botanical Latin (Figueiredo $\&$ al. 2010a,b). In fact, Jørgensen's paper has done enough to show that it is indeed now time to let go of Latin as the mandatory language in which to require the provision of a diagnosis.

\section{aCKNOWLEDGEMENTS}

We thank Prof. John McNeill for comments on the manuscript.

\section{DITERATURE CITED}

Figueiredo, E., Moore, G. \& Smith, G.F. 2010a. Latin diagnosis: Time to let go. Taxon 59: 617-621.

Figueiredo, E., Moore, G. \& Smith, G.F. 2010b. (115-116) Proposals to eliminate the Latin requirement for the valid publication of plant names. Taxon 59: 659-660.

Jørgensen, P.M. 2010. Latin diagnosis. Taxon 59: 1196. 